\title{
Agricultura E AGROECOLOGIA: POSSIBILIDADES DE UM NOVO MERCADO SUSTENTÁVEL
}

Gabrielle Jacobi Kölling*

Gernardes Silva Andrade**

\section{Resumo}

A sustentabilidade passou a ser pauta constante, é nesse cenário que a agroecologia se apresenta como forma de agricultura sustentável que retoma as concepções agronômicas anteriores à chamada Revolução Verde. É possível produzir de modo sustentável, com manejos que usem como paradigma práticas da agricultura orgânica e o emprego de tecnologias limpas, gerando menos externalidades ambientais negativas e, consequentemente, mais sustentabilidade. Assim, o objetivo do presente artigo é analisar como a agroecologia e os seus desdobramentos no cenário brasileiro.

Palavras-chave: Agroecologia; sustentabilidade; mercado; políticas públicas; agricultura familiar.

\section{AGRICULTURE AND AGROECOLOGY: POSSIBILITIES OF A NEW SUSTAINABLE MARKET}

\begin{abstract}
Sustainability has become a constant issue, it is in this scenario that agroecology presents itself as a form of sustainable agriculture that resumes agronomic concepts prior to the socalled Green Revolution. It is possible to produce in a sustainable way, with managements that use organic farming practices as a paradigm and the use of clean technologies, generating less negative environmental externalities and, consequently, sustainability. Thus, the objective of this article is to analyze how agroecology and its consequences in the Brazilian scenario.
\end{abstract}

Keywords: Agroecology; sustainability; market; public policy; family farmimg.

\section{Introdução}

$\mathrm{Na}$ sociedade atual o tema do agronegócio gera muitas discussões, especialmente no

\footnotetext{
" Doutora em Direito Público (Unisinos). Mestre em Direito Público (Unisinos). Especialista em Direito Sanitário (ESPRS e Universidade de Roma Tre). Bacharel em Direito (Unisinos). Professora concursada na Universidade Municipal de São Caetano - USCS. Professora dos Mestrado Profissional em Direito do CERS Centro Educacional Renato Saraiva. Líder do Grupo de Pesquisa do CNPq "Tutela jurídica da saúde ambiental". E-mail: koll.gabrielle@gmail.com. Endereço postal: Avenida Goiás, 3400, Barcelona, São Caetano do Sul-SP, CEP: 09.550-051.

** Mestrando em Direito (Faculdade CERS). Especialista em Gestão Pública (IFPE). Bacharel em Direto (ASCES/UNITA). Agente de Desenvolvimento do Banco do Nordeste S. A., E-mail: gernardes@yahoo.com.br. Endereço Postal: Rua Sete de Setembro, 09, andar 01, Centro, Surubim-PE, CEP: 55.750-000.
} 
tocante aos modos tradicionais de produção. A sustentabilidade dos modos de produção passou a ser pauta constante e é nesse cenário que a agroecologia se apresenta como uma forma de agricultura sustentável que retoma as concepções agronômicas anteriores à chamada Revolução Verde. Consideram-se as chamadas práticas de agricultura que incorporam as questões sociais, políticas, culturais, energéticas, ambientais e éticas.

É possível produzir de modo sustentável, com manejos que se enquadram no conceito de agroecologia e que usem como paradigma práticas da agricultura orgânica e o emprego de tecnologias limpas, gerando menos externalidades ambientais negativas e, consequentemente, mais sustentabilidade. Nasce, assim, um novo mercado na produção agrícola: a agroecologia.

O conceito de agroecologia pode ser entendido como a remediação inadiável ao agravamento das condições ambientais, sociais e políticas causadas pela forma de desenvolvimento econômico vigente. A proposta da agroecologia é uma revisão dos métodos convencionais de manejo da terra em grande escala.

Assim, o objetivo do presente artigo é analisar como a agroecologia, em função de sua base científica e caráter multidisciplinar, pode ser de grande valia para a compensação de desigualdades socioeconômicas forjadas desde os primórdios da colonização. Além do mais, em perspectiva mundial, é plausível pugnar pela tese de que é um fator relevante no alcance dos Objetivos de Desenvolvimento Sustentável.

Assim sendo, a priori, será contextualizado o processo de colonização do território brasileiro com seus ciclos econômicos mais vultosos e as sequelas da "empresa agromercantil" que implicam contemporaneamente. Posteriormente, o debate concernirá na relação Sustentabilidade e Agroecologia, e de como esta pode ser um vetor indutor de desenvolvimento sustentável em escala local e global. Findando, este ensaio abordará a despeito das políticas de agroecologia no Brasil, relatando sobre seus limites, possibilidades e articulações enquanto política pública.

No tocante à metodologia, utilizar-se-á o método descritivo-analítico. Quanto às técnicas, pode-se dizer que a bibliográfica será crucial para a análise de material já publicado acerca do tema, constituído, principalmente, de livros, artigos de periódicos e, atualmente, via eletrônica, nacionais e internacionais. A análise documental será relevante para os materiais que não receberam tratamento analítico. As fontes documentais podem ser documentos reservados em arquivos de órgãos públicos e instituições privadas (associações científicas), regulamentos, ofícios, boletins. 


\section{Contextualização do processo de colonização no Brasil}

Em vista do modelo de colonização empregado no Brasil, baseado na exploração de latifúndios e no cultivo de matérias primárias sob o manejo da monocultura extensiva, em pleno século XXI, seu espaço rural reflete marcas de insustentabilidade. Hoje, este predomínio permanece sob o título de agronegócio e seu produto, continua voltado à exportação e tem a alcunha de commodities.

Inicialmente, quanto aos formatos de colonização empregados por aqui evidencia-se a exploração do território baseada no Mercantilismo (acumulação primitiva de Capital), todavia com uma interface fortemente agrícola: o Brasil como uma empresa agrícola, FURTADO (1973, p. 93), e a mercê das necessidades externas. Assim, a partir de 1532, mormente nas capitanias de Pernambuco e São Vicente, foram estabelecidas bases na agricultura, no patriarcalismo, na junção da cultura econômica e social do colonizador prevalecendo-se sobre os costumes nativos e no trabalho escravo (primeiramente de indígenas, posteriormente de africanos).

Diante desta temática são indispensáveis as contribuições de Gilberto Freyre (2003) abordadas no clássico escrito Casa Grande \& Senzala: formação da família brasileira sob o regime da economia patriarcal, cuja primeira edição foi disponibilizada em 1933. Ressalte- se, aliás, que o comércio de vidas cativas em si era uma cadeia angariadora de divisas para metrópole e para terceiros (sejam eles nações ou entidades), não ficando restrita a utilização de mão de obra nos principais ciclos econômicos (a exemplo da cana-de açúcar, da mineração, do café, entre outros), perdurando (oficialmente) até 1888.

Sob o prisma econômico, a ocupação das terras brasileiras nos séculos XVI e XVII ficou mais concentrada no litoral e na zona da mata do Nordeste. Este fato foi objeto de estudo da tese de doutorado de Celso Furtado: A Economia Colonial no Brasil nos séculos XVI e XVII (1948), cujos estudos foram integrados ao livro Formação Econômica do Brasil, publicado em 1959. Analisando esta obra, Araújo e Santos (In Araújo et al. 2009, p.177) compreendem que, dentre suas inúmeras contribuições, uma delas "é a identificação das raízes da diversa e desigual organização do território brasileiro".

Já entre os séculos XVIII e XIX, a potência dos ciclos econômicos deslocam-se do Nordeste, para o Sudeste. A colonização desta região foi impulsionada após a descoberta de ouro e diamantes nas Minas Gerais (nos últimos anos do final do século XVII). Nos empreendimentos de mineração além dos escravos, atuando nas lavras, havia a figura dos faiscadores, os quais eram trabalhadores livres e autônomos (PRADO JÚNIOR, 1961, p. 173 e 
174). Toda a movimentação ocasionada por este novo fluxo migratório fez eclodir vários povoados cravejados às margens da "rota do ouro" e, a posteriori, a criação da "intendência dos diamantes."

Chegando em meados do século XIX, se intensifica o povoamento do território de São Paulo, mais especificamente no Vale do Paraíba e no Oeste Paulista, ensejado pela exploração da cultura cafeeira. Neste período, se por um lado era pujante a expansão desta cadeia produtiva, por outro disparava o alerta para substituição dos escravos condicionados pelas conquistas dos movimentos abolicionistas (culminando, em tese, em 1888).

Existiam basicamente três opções de trabalhadores: o escravo, o imigrante e o nacional livre. Em São Paulo, durante os anos de 1877 a 1880, o estoque de cativos manteve-se praticamente inalterado e a entrada de estrangeiros ainda era relativamente pequena, principalmente quando comparada aos números da imigração em massa a partir do final da década de 1880. A população livre pobre, entretanto, avolumava-se na província. Contribuíram para isso o crescimento vegetativo, a migração interna e as diversas formas de emancipação dos escra- vos (GONÇALVES, 2014).

No entanto, independentemente de se ter ultrapassado a era colonial, de ter sido (gradualmente) reconhecida a sua independência, de tornar-se uma república e de alçar status de Estado Democrático de Direito, a aparente progressão política nem de longe propiciou alterações significativas no panorama socioeconômico. Isto porque, de acordo com Sérgio Buarque de Holanda (1995, p. 73):

Toda estrutura de nossa sociedade colonial teve sua base fora dos meios urbanos. É preciso considerar esse fato para se compreenderem exatamente as condições que, por via direta ou indireta, nos governaram até muito tempo depois de proclamada nossa independência polí- tica e cujos reflexos não se apagaram ainda hoje.

Mais que isso, não bastasse as contemporâneas imposições neocoloniais advindas de grandes conglomerados empresariais transnacionais, muitos dos sucessores, patrimonialmente ou ideologicamente, daqueles "donatários de sesmarias" continuam a submeter a grande maioria da população a bel-prazer de seus caprichos.

Por este prisma, no quadro atual, percebe-se uma robusta elite no campo com potente representação no congresso nacional, grande concentração de renda, usuária de novas tecnologias e assistência técnica especializada, impulsionada por financiamento (mormente, estatal) e detentora de conhecimentos relativos à inovação e a empreendedorismo. Assim, quanto às perspectivas, notadamente capitalistas, focadas no lucro, na produção e na produtividade é fácil este agro se dizer pop. 
Em contrapartida, quando se mira para o outro lado da cerca, da "rodagem", ou do ribeirão estão os sujeitos que interessam a este trabalho: os agricultores familiares de produção agroecológica. Estes, em um país em que a desigualdade social é tão peculiar, da mesma maneira que outros grupos vulneráveis, tem dificuldades de desfrutar de direitos básicos ou sofrem violações, consoante Lima Júnior (2001, p. 90).

Neste sentido, Boaventura Souza Santos (1999, p. 223), dissertando sobre os "novos movimentos sociais", ressalta a crítica destes, tanto à emancipação social socialista quanto à regulação social capitalista. Ademais, ao pontuar outros contornos de opressão transcendentes às relações de produção, tais como o machismo, a poluição, o racismo, o produtivismo e a guerra, estes agrupamentos contestam por um novo paradigma social, frente aos excessos de regulação da modernidade, calcados na cultura e na qualidade de vida em detrimento do aspecto patrimonial.

Além disso, este sociólogo obtempera que tais abusos interferem no modo de trabalho e produção bem como no modo de vida e descanso das pessoas e, por outro lado, reflete a alienação e os conflitos internos do indivíduo decorrentes da pobreza e das realizações sociais. Ou seja, não são sentidos apenas por determinada classe social, decerto, afligem grupos sociais transclassistas (sic) e toda sociedade (Ibid).

Não obstante, os grupos de resistência da zona rural emergem, em princípio, para combater violações de direitos. Este posicionamento é bastante salutar ao Estado Democrático de Direito, ainda mais em sociedades manchadas pelo regime de servidão, em que tais grupos estão sujeitos à pobreza extrema e à fome desde as primeiras ações de colonização do Brasil. Neste diapasão, é pertinente a contribuição de Gladstone Leonel Júnior, ao dissertar acerca dos fundamentos histórico-teóricos do campesinato e os elementos para o desenvolvimento da agroecologia.

O referido professor identifica nos trabalhadores tanto uma função primordial tangente a "resistência agroecológica frente ao modelo predatório vigente", quanto atos de solidariedade direcionados aos demais obreiros (urbanos e rurais assalariados) dominados pelos moldes de produção posto. Outrossim, baliza “a importância da revitalização do campesinato na agricultura sustentável de fato, ou seja, mantendo as bases de reprodução no manejo dos seus recursos naturais" (2016, p. 30).

A agroecologia tem por significado "novos jeitos" ou o resgate de se fazer agricultura (aspecto econômico) sem explorar os seres humanos (aspecto social) nem degradar o meio ambiente (aspecto ambiental). Fica claro que seu desígnio é a produção de alimentos ao 
passo que proporciona justiça social e equilíbrio ecológico de todo sistema.

Assim, se adequa perfeitamente à concepção de desenvolvimento sustentável. Com vistas ao relatório Nosso Futuro Comum (1978), liderado pela médica Gro Harlem Brundtland, a Organização das Nações Unidas (ONU) conceitua o desenvolvimento sustentável como "o desenvolvimento que encontra as necessidades atuais sem comprometer a habilidade das futuras gerações de atender suas próprias necessidades" (NAÇÕES UINIDAS: MEIO AMBIENTE, [s.d.]). Como disposto, a agroecologia se apresenta como uma atividade antrópica sustentável por excelência.

\section{Sustentabilidade e Agroecologia}

É relevante a proposição dos 17 Objetivos de Desenvolvimento Sustentáveis (ODS) pela Organização das Nações Unidas. Esta ação está no espectro da Agenda 2030, cuja pretensão é transformar o mundo por intermédio do desenvolvimento sustentável. Mais uma vez, são lançadas políticas públicas, de dimensão global com os devidos ajustes locais, vislumbrando-se ser um artifício mais adequado para alcançar a exigibilidade de direitos.

Os ODS's têm por finalidade a concretização de direitos humanos, mas também "são integrados e indivisíveis, e equilibram três dimensões do desenvolvimento sustentável: a econômica, a social e a ambiental" (ONU, Agenda 2030). Em virtude de seu lastro principiológico, bem como seu caráter interdisciplinar não parece ser difícil ilustrar a relevância da agroecologia na maioria dos ODS (infra), especialmente no ODS 2.

Em nível mundial, presume-se que esta atividade é uma alternativa adequada para “acabar com a fome, alcançar a segurança alimentar e melhoria da nutrição e promover a agricultura sustentável” (NAÇÕES UINIDAS: ODS2, [s.d.]). Esta percepção decorre do Objetivo de Desenvolvimento Sustentável 2 (ODS 2), sob o título de "fome zero e agricultura sustentável".

Em nível nacional, há de se alertar as ações de enfretamento aos impactos decorrentes do uso de agrotóxicos frente à saúde humana e ao meio ambiente previstas na PALANPO/2016-2019. Ou seja, além de propor uma alimentação saudável, questões de Saúde Pública e Segurança Alimentar não podem ser dissociadas desta cadeia econômica.

A segurança alimentar é uma responsabilidade compartilhada. Governos, órgãos econômicos regionais, organizações das Nações Unidas, agências de desenvolvimento, organizações comerciais, grupos de consumidores e produtores, instituições acadêmicas e de pesquisa e entidades do setor privado devem trabalhar juntos em questões que nos afetam (NAÇÕES UNIDAS: FAO, 2019). 
Destarte, Azevedo e Pelicioni (2011, p. 715), defendem “a Agroecologia como uma estratégia intersetorial de promoção da saúde, de sustentabilidade e de segurança alimentar e nutricional". À época, estas pesquisadoras, já assinalavam um cenário desafiador na academia tangente ao exercício de correlacionar saúde pública e sistemas agroalimentares, pois a este não lhes eram oportunizados a atenção devida.

Por sua vez os consumidores, cautelosos com sua saúde e na promoção de bem-estar, seja no plano local, seja no plano mundial, estão aumentando a demanda por alimentos saudáveis paulatinamente. Neste item, cabe esclarecer a diferença entre orgânico e agroecológico, embora no mercado possam ser frequentemente confundidos ou tidos como uma única espécie.

Inclusive, a própria Lei $\mathrm{n}^{\circ} 10.831 / 2003$, em seu artigo $1^{\circ}$, perfaz esta confusão, de modo que um termo poderia ser trocado por outro (e vice-versa). Já neste mesmo artigo, em seu parágrafo $2^{\circ}$, se reproduz, textualmente, o equívoco de tratar agroecológicos como espécie do gênero orgânicos. Mais adiante, prevalecerá tese divergente a este respeito. Apesar de sua redação ser tendenciosa no sentido reluzir um nicho de mercado específico (para os orgânicos), o mais admirável, para todos os efeitos, é que compreensão é, eminentemente, agroecológica.

Conquanto sua técnica produtiva prescinda de adubos sintéticos e agrotóxicos e se prese pelo uso responsável dos recursos naturais, as culturas orgânicas nem sempre estão vinculadas a um contexto social justo. Isto, porque este tipo de atividade pode vir a ficar concentrada em produtores ou empresas rurais, as quais estão obstinados pelo lucro (ao entregar um alimento mais caro), se utilizam de atravessadores e, nem sempre, garantem direitos aos trabalhadores (BRITTO, 2020).

Portanto, o manejo orgânico, conforme Gladstone Leonel Júnior (2016, p. 124), "trata-se de uma agricultura mais interessada em uma fatia de mercado (daqueles/as que priorizam o consumo de um alimento mais saudável mesmo pagando valores mais altos), do que na produção massiva e acessível de alimentos de qualidade à população”.

A contrário censo, a Agroecologia tem o condão ratificar a questão econômica, social, cultural, entre outras áreas, referentes ao fortalecimento da agricultura familiar ao passo que reforçam sua oportunidade de fornecer alimentos saudáveis e com preços acessíveis a toda população (rural e urbana). Um ponto de conexão entre estes produtores e os consumidores são as feiras agroecológicas. Tais transcendem a mera relação de consumo 
presentes nos supermercados ou nas feiras tradicionais.

Nos espaços de convivência e comercialização agroecológica, é onde estes sujeitos se depararam e que ocorre a venda direta dos alimentos, sem o intermédio de qualquer atravessador, implicando em relações sociais (trabalho e remuneração) mais justas. Além de tudo, cria-se um laço de confiança recíproca entre vendedor e comprador, o qual dá abertura para este expor suas necessidades, desejos, críticas e preferências diretamente a quem produz.

Outra alternativa para escoar a diversidade de artigos (in natura ou beneficiados) é aderindo programas institucionais referendados por políticas públicas, porém o tema será discutido na próxima seção. Para as modalidades de venda citadas, o agricultor familiar carece de estar cadastrados no Ministério da Agricultura e Pecuária e vinculados a uma Organização de Controle Social (OCS) (MAPA, [s.d.]).Caso queira atingir outros mercados será necessário obter certificação orgânica por auditoria ou por organismo participativo (OPAC), e atender às disposições da Lei 10.831/2003, regulamentada pelo Decreto 6.323/2007.

Em particular, a regularização produtiva, via OCS, é um passo essencial para seu o empoderamento e sentimento de pertencimento a este universo. "As OCS geram credibilidade pela sociedade, a partir da interação de pessoas ou organizações com base na confiança, na participação comprometimento, transparência e responsabilidade solidária” (Id., 2020, p. 13).

Ademais, um dado extraordinário a ser reverberado é o vigor da produção oriundo da agricultura familiar. Conforme a Organização das Nações Unidas para Alimentação e Agricultura (FAO), "os agricultores familiares produzem $80 \%$ dos alimentos do mundo e são importantes impulsionadores do desenvolvimento sustentável" (FAO BRASIL, c2020). Corroborando com este pensamento, em 2018, como desdobramento do Segundo Simpósio Internacional sobre Agroecologia (Roma), a FAO decide por preterir o ideário da "revolução verde", pautada na agricultura intensiva (iniciada pós Segunda Guerra Mundial). Sem embargo, assente a agroecologia como sistema alimentar perene, atento à preservação ambiental e à diversidade produtiva.

Desta feita, foi publicada a iniciativa para ampliar a escala da agroecologia, cujo objetivo é transformar a alimentação e os sistemas agrícolas aliados aos ODS.

Este documento presenta la Iniciativa para ampliar la escala de la Agroecología, una visión para ampliar el alcance de la agroecologíaa y transformar los sistemas alimentarios y agrícolas para alcanzar los ODS. El documento responde a cuatro cuestiones clave: ¿Cuál es el potencial de la agroecología para contribuir a la Agenda 2030? (Sección 1); ¿Cuáles son los desafíos y oportunidades ligados a ampliar la escala de la agroecología? (Sección 2); ¿Cuáles son las principales áreas de trabajo sobre las que la 
Iniciativa para ampliar la escala de la Agroecología se debería centrar? (Sección 3) y ¿Cuál es el camino a seguir para la Iniciativa para ampliar la escala de la Agroecología? (Sección 4) (FAO, 2018, grifos do autor).

Para se alcançar esta aspiração da agroecologia é fundamental conciliar a agricultura familiar à sustentabilidade. É possível produzir, movimentar o mercado e respeitar o adequado manejo ecológico dos recursos naturais. Todavia, para isso, é conditio sine qua non, dentre outros aspectos, existir consciência coletiva e social para romper o paradigma tradicional de produção na agricultura. Romper com o "velho" e aceitar o "novo nem tão novo assim" demanda coragem, sociedade e ecologia podem conviver e evoluir em conjunto.

\section{Resultados e discussão - Política de Agroecologia no Brasil: limites e possibilidades}

Para enfrentar a discussão paradigmática relacionada ao que de fato incorpora uma política pública (que é distinta de política de governo), é necessário retomarmos alguns postulados relacionados ao Estado, a sua função e visualizar a relação da agroecologia enquanto política pública com a sociedade.

A Política Nacional de Agroecologia e Produção Orgânica (Pnapo) foi criada em 2012, ou seja, é bastante recente, quiçá incipiente. Com um histórico tão recente, é perceptível que a agroecologia não foi e ainda não é pauta do Estado.

Em tempos de discursos com pretensão de correção e de instabilidade política, é sempre bom recordar a lição de Habermas: não é a contingência cega das circunstâncias decepcionantes que assinala o fracasso dos juízos e normas morais, mas antes a dor dos ofendidos, cuja voz se faz ouvir na contradição e na indignação dos adversários que esposam orientações de valor diferentes. Esse fracasso exige uma série de processos de aprendizado pelos quais as partes conflitantes chegam a descentralizar suas perspectivas egocêntricas e etnocentricas de tal modo que possam incluir-se reciprocamente uma a outra na construção conjunta de um mundo mais amplo de relações interpessoais legítimas. Cabe à ética do discurso provar que a necessária dinâmica de 'cada qual ver o que o outro ve' está embutida nos pressupostos pragmáticos do próprio discurso prático (HABERMAS,2007, p. 66-67). O fracasso (ou insuficiência) da tardia política nos convida a refletir sobre os processos de aprendizado sobre o que temos de agroecologia, qual é a sua importância na sociedade contemporânea e o que esperamos do Estado em termos de agroecologia e de política pública.

Em última análise, é condição de possibilidade ouvir mais a dor dos ofendidos e, sobretudo, buscar o constante aprendizado das práticas cotidianas voltadas ao cuidado com as pessoas, com a agricultura, com a terra, as quais estão acima de quaisquer projetos transitórios 
de poder. Os direitos fundamentais, individuais e sociais (dentre os quais a saúde, a alimentação, dentre outros envolvidos no tema da agroecologia) não são um problema de esquerda ou de direita, tão em voga em tempos de discursos de fratura social, mas inerentes à própria condição humana. Precisamos superar as perspectivas egocêntricas em prol da construção de uma autêntica República, na qual a igualdade material não seja uma moeda de troca, mas pressuposto fundamental da cidadania livre e com capacidade de autodeterminação, capacidade, esta, inclusive para escolher qual tipo de política pública queremos para a agroecologia.

A Política Nacional de Agroecologia e Produção Orgânica (Pnapo) foi criada em 2012, com a pretensão de integrar, articular e adequar as políticas públicas que contribuem para a produção sustentável de alimentos saudáveis e livres de contaminantes químicos, aliando o desenvolvimento rural com a conservação dos recursos naturais e a valorização do conhecimento dos povos e comunidades tradicionais.

Para compreender a política pública é necessária uma análise do seu processo de construção com base nas percepções dos representantes das diversas instituições do governo e da sociedade civil que participam da sua gestão. Segundo o IPEA (2017), para compreender o processo de construção da agroecologia foram realizadas entrevistas semiestruturadas diversos setores, dentre os quais com representantes dos atores que participaram da construção da política. Os dados obtidos mostraram que as agendas da agroecologia e da produção orgânica foram lentamente construídas dentro do governo por força das pressões da sociedade civil organizada, do terceiro setor. Outro aspecto relevante para a construção dessas agendas foi o fortalecimento dos espaços de discussão, participação e articulação proporcionados pelos conselhos e comissões de participação social. Nota-se, então, um amplo espaço democrático, com participação da sociedade na tomada de decisão em relação à concepção da Pnapo (IPEA, 2017).

O desenho histórico da pesquisa do IPEA mostra que os espaços de diálogo proporcionados pela Comissão Nacional de Agroecologia e Produção Orgânica (Cnapo), formada por representantes do governo e de entidades da sociedade civil, e a Câmara Interministerial de Agroecologia e Produção Orgânica (Ciapo), composta por representantes dos ministérios que atuam na política, foram fundamentais, pois forjaram a construção participativa entre governo e sociedade e estimularam uma abordagem interministerial dentro do âmbito governamental (IPEA, 2017). Os maiores desafios são estão ligados ao processo de aprimoramento da gestão intersetorial e a ampliação da prioridade da Pnapo dentro do próprio 
governo (esse é o desafio do passado, do presente e do futuro). A manutenção da política dependerá, também, do reconhecimento social e a atuação do governo para incentivar as práticas de agroecologia.

Partindo deste pressuposto, é conveniente trazer à baila a articulação entre políticas públicas pautadas em alimentação, quais sejam o Programa de Aquisição de Alimentos (PAA) e o Programa Nacional de Alimentação Escolar (PNAE). Este programa tem por escopo oferecer alimentação escolar e promover educação alimentar e nutricional aos estudandes da educação básica da rede pública (PNAE, c2017). Graças à Lei 11.947/2009, o seu artigo 14 estabelece que:

Do total dos recursos financeiros repassados pelo FNDE, no âmbito do PNAE, no mínimo 30\% (trinta por cento) deverão ser utilizados na aquisição de gêneros alimentícios direta- mente da agricultura familiar e do empreendedor familiar rural ou de suas organizações, pri- orizando-se os assentamentos da reforma agrária, as comunidades tradicionais indígenas e comunidades quilombolas (grifos nossos).

Regulamentando esta política pública, repetindo orientação de anos anteriores, a Resolução n ${ }^{\circ} 06$ do Ministério da Educação, orienta, quando possível, por priorizar a aquisição de alimentos orgânico e/ou agroecológicos no ente federativo onde se localize a escola (art. 23). Mais adiante, prevê a possibilidade de “[...] acrescer aos preços desses produtos em até 30\% (trinta por cento) em relação aos produtos convencionais [...]” (§ $5^{\circ}$, art. 31).

Neste recorte, a garantia de mercado para os produtos agroecológicos da agricultura familiar não condiz, necessariamente, com acesso eficaz a essa política. Isto, em muito, dependerá das governanças locais, pois é a partir de atividade de fiscalização e ações de controle social das entidades competentes (tal qual os conselhos e outros coletivos dasociedade civil) que irão cobrar às esferas da administração pública a aplicação destes dispositivos (supra). Ainda assim,

Iniciativas como como o Programa de Aquisição de Alimentos (PAA) e o Programa Nacional de Alimentação Escolar vêm sendo apontados como as principais políticas públicas de incentivo à produção sustentável e o fornecimento de alimentos saudáveis à população. Os problemas que denúncias recentes apontaram no tocante à regulamentação desses programas, no entanto, denunciam que é preciso pensar nas condições efetivas que o Estado oferece para a consolidação da Agroecologia e da produção orgânica enquanto modelos viáveis de uma produção agroalimentar sustentável (ISAGUIRRE-TORRES e FRIGO, 2013, p.16).

Atinente ao PAA, este foi constituído pelo artigo 19 da Lei 10.696/2003, tal como é regulamentado pelo Decreto 7.775/2012. Seu objetivo precípuo é servir como um mecanismo 
voltado à ascensão da agricultura familiar e ao combate à insegurança alimentar. Observe-se que no referido decreto (art. $4^{\circ}$, I), fica bem delineado o sujeito beneficiado como:

indivíduos em situação de insegurança alimentar e nutricional, aqueles atendidos pela rede socioassistencial, pelos equipamentos de alimentação e nutrição, pelas demais ações de alimentação e de nutrição financiadas pelo Poder Público e, em condições específicas definidas pelo GGPAA, aqueles atendidos pela rede pública de ensino e de saúde e que estejam sob custódia do Estado em estabelecimentos prisionais e em unidades de internação do sistema socioeducativo.

De outro lado, nos incisos seguintes, também esclarece os demais atores envolvidos nesta política, como os beneficiários fornecedores (a exemplo dos agricultores familiares), organizações fornecedoras, unidades recebedoras, órgão compradores e a "chamada pública" como procedimento administrativo a ser empregado. Nesta esteira, no caso dos agricultores familiares, o PAA chama atenção por impulsionar o aumento de renda e a melhoria na qualidade de vida. Importa salientar, para a definição de preços de artigos agroecológicos (e orgânicos) deste programa, a mesma possibilidade de acréscimo de até 30\%a despeito dos itens convencionais prevista no PNAE (SEDS, [s.d.]).

Para além das políticas públicas (como a PNAPO) e de uma agenda sustentável consistentes que agreguem o debate e o "fazer" agroecológico, este conjunto, por vezes, "não é suficiente quando o sistema jurídico mantém-se no reconhecimento de normativas que favorecem a manutenção dos riscos sociais e ambientais do modelo de produção dominante" (ISAGUIRRE-TORRES e FRIGO, 2013, p.18). Esta realidade exige exponencial engajamento dos atores imbuídos em apoderar-se de um ambiente rural equilibrado e do imperativo de firmar resistência.

Agroecologia, sustentabilidade e meio ambiente são discussões correlacionadas, a agenda ambiental está conectada à agricultura, e não é de hoje. Devido a relevância do tema para o meio ambiente, foi desenvolvido por meio do MMA (Ministério do Meio Ambiente) a Agenda 21 que tem por finalidade desenvolver fundamentos para contribuir com as análises políticas que desenvolvam na sociedade de forma participativa, bem como controle social e suas estruturas, segundo Fonseca (2009), ainda afirma que a Agenda 21 precisa motivar ações do governo em paralelo a sociedade para um desenvolvimento sustentável. O número 21 é oriundo a outra finalidade que é alcançar 21 locais dessas ações e análises políticas.

Embora a Agenda 21, cujo seu conceito chave é o desenvolvimento sustentável, foi um documento elaborado na Agenda Rio 92 em uma conferência onde representantes de 178 países reuniram-se para tratar de temas acerca do meio ambiente e sua sustentabilidade. No 
entanto, o processo da Agenda 21 foi viabilizado apenas em 1997 pela constituição da Comissão de Políticas de Desenvolvimento Sustentável. A CPDS decidiu que a AG21 seria formada por seis conteúdos, listados a seguir com os respectivos consórcios responsáveis, quais sejam: 1) Cidades sustentáveis - Consórcio Parceria 21;2) Redução das desigualdades sociais - Consórcio Parceria 21; 3) Agricultura sustentável - Consórcio Museu Emílio Goeldi; 4) Gestão de recursos naturais - Consórcio TCBR/Funatura; 5) Ciência e tecnologia para o desenvolvimento sustentável - Consórcio CDS-UnB/Abipti.

Após várias reflexões, a AG21 apesar de sua importância histórica neste processo, não foi capaz de gerar políticas e ações concretas em escala nacional para a promoção do desenvolvimento sustentável. O processo da AG21 Brasileira se desenvolveu como um projeto, que teve seu produto final - e sua conclusão - com a entrega dos documentos intitulados Agenda L1 Brasileira: ações prioritárias e resultado da consulta nacional (FONSECA, 2016). Nota-se, por tanto, que a sustentabilidade vinculada à agricultura já é um tema que foi discutido na agenda ambiental desde a década de 90.

É nesse contexto histórico de formação e influências que a agroecologia é forjada como um paradigma agroecológico, como um enfoque de intervenção multidisciplinar, que vem sendo construído a partir de uma cientificamente comprovada crise no atual modelo tecnológico e de organização da produção dominante na agricultura (MARTINEZ, 1992).

A construção da política da PNAPO é, em última análise, a síntese de uma reflexão crítica sobre o modelo de produção agrícola com base na revolução verde e na modernização da agricultura, historicamente combatida no Brasil devido aos seus impactos sobre o meio ambiente. Considerando, incialmente, a monocultura de commodities para exportação, o padrão de produção difundido pelo paradigma da revolução verde é muito prejudicial ao ambiente, tendo em vista que ele diminui a biodiversidade dos agroecossistemas, bem como a sua estabilidade e abrindo, assim, espaço para o ataque de pragas e doenças. Não podemos olvidar que isso gera uma demanda grande e crescente por agrotóxicos e fertilizantes químicos, os quais impactam muito negativamente a saúde humana, bem como o meio ambiente, visto que podem poluir as águas e o solo, causando, por sua vez, a perda de biodiversidade e dos seus serviços ecossistêmicos. No ano de 2008, o Brasil assumiu o posto de maior mercado de agrotóxicos do mundo, isso gera uma contaminação dos alimentos em escala bastante grande (CARNEIRO et al, 2015).

Na política de agroecologia nota-se a fragilidade em relação ao tema dos agrotóxicos. $\mathrm{O}$ atual sistema agrícola, com a justificativa insustentável de atender às demandas 
populacionais, compeliu a mecanização e a crescente utilização de insumos para o seu desenvolvimento, como é o caso dos agrotóxicos. Esse uso demasiado de substâncias agrotóxicas afeta não somente os alimentos, mas também, por via de consequência, os animais humanos que os consomem, avariando a sua a incolumidade físico psíquica (FIORILLO, 2015). O tema deveria ser tratado e enfrentado na política, visto que o art. 225 da Constituição Federal de 1988 , no $\S 1^{\circ}$, inciso V do artigo, prevê que incumbe ao poder público controlar a produção, a comercialização e o emprego de técnicas, métodos e substancias que comportem riscos para a qualidade de vida e ao meio ambiente. Assim, demonstra-se que o texto constitucional não proíbe o uso de agrotóxicos, contudo, o limita ao responsabilizar o poder público pelo controle das atividades, assegurando assim a efetividade do direito ao meio ambiente saudável. A própria FAO eleva a agroecologia como viável para produção de alimentos e preservação da biodiversidade, à medida que rompe com seu alinhamento, de quase meio século, com a "Revolução Verde" (manejo intensivo).

Nota-se, ainda, que a política usa o termo agroecologia indistintamente, sem o rigor e cuidado necessários. A agroecologia apresenta-se como ciência ou disciplina científica que apresenta uma série de princípios (por isso é área específica do conhecimento), conceitos e metodologias para estudar, analisar, dirigir, desenhar e avaliar agroecossistemas, com a pretensão de possibilitar a implantação e o desenvolvimento de padrões de agricultura com maiores níveis de sustentabilidade. Assim, a agroecologia proporciona bases científicas para apoiar o processo de transição a estilos de agricultura sustentável nas suas diversasmanifestações na sociedade atual. (ALTIERI, 1989). É a partir dessa ciência que se pode implementar, na prática, novos instrumentos de produção agrícola.

Por fim, percebe-se que a agroecologia constitui um campo de estudos que pretende o manejo ecológico dos recursos naturais, para, através de uma ação social coletiva de caráter participativo, para reconduzir ou readequar a coevolução social e ecológica, mediante controle das forças produtivas, deixando de lado as formas degradantes e espoliadoras da natureza e da sociedade ALTIERI, 1989). Trata-se, pois, de uma ruptura com os modelos tradicionais, a ruptura gera impacto, movimenta.

Eis alguns dados. Nestes não há distinção entre orgânicos e agroecológicos, ambos são tratados como uma única espécie.

(i) O percentual de participação dos orgânicos nas compras feitas pela Companhia Nacional de Abastecimento (Conab), no Programa de Aquisição de Alimentos (PAA), triplicou nos últi- mos cinco anos. Segundo a Conab, no ano passado, $6 \%$ dos alimentos adquiridos nas moda- lidades executadas 
pela Companhia eram orgânicos. Em 2013, esse índice era de 2,2\% ${ }^{1}$.

(ii) De 2013 a 2018, foram adquiridos por meio do PAA cerca de 11,6 mil toneladas de produtos orgânicos, somando quase R \$ 30 milhões. Quando se considera todo o volume comerciali- zado pelo programa desde 2013, a participação dos orgânicos ainda fica em torno de $2,5 \%{ }^{2}$.

(iii) A ampliação anual da compra de produtos orgânicos é uma das metas previstas no Plano Nacional de Agroecologia e Produção Orgânica (Planapo), em vigor desde 2016. No âmbito do PAA, o plano tinha o objetivo de garantir, até 2019, que pelo menos 5\% dos recursos aplicados anualmente pelo PAA fossem para alimentos orgânicos, da sociobiodiversidade e de base agroecológica ${ }^{3}$.

(iv) O mercado brasileiro de orgânicos faturou no ano passado $\mathrm{R} \$ 4$ bilhões, resultado 20\% maior do que o registrado em 2017, segundo o Conselho Brasileiro da Produção Orgânica e Sus- tentável (Organis), que reúne cerca de 60 empresas do setor ${ }^{4}$.

(v) Em 2012, havia no país quase 5,9 mil produtores registrados e março de 2019, já registrou mais de 17,7 mil, crescimento de $200 \%$. No período também cresceu o número de unidades de produção orgânica no Brasil, saindo de 5,4 mil unidades registradas, em 2010, para mais de 22 mil no ano passado, variação de mais de $300 \%{ }^{5}$.

(vi) Apesar do crescimento exponencial dos registros no cadastro, o universo de produtores or- gânicos no Brasil pode ser muito maior. Antes do decreto que regulamenta o setor entrar em vigor, em 2007, o Instituto Brasileiro de Geografia e Estatística (IBGE) identificou 90 mil produtores que se autodeclararam como orgânicos. "A tendência é de crescimento permanente", afirmou Virgínia Mendes Lira, que chefia a Coordenação de Produção Orgânica, setor do Mapa responsável pelo Cadastro Nacional de Produtores Orgânicos e pela execução das ações relacionadas ao setor ${ }^{6}$.

(vii) Desde 2009, o Programa estabelece o percentual mínimo de 30\% para produtos da agricul- tura familiar nas aquisições das escolas municipais e estaduais do país. Atualmente, cerca de $43 \%$ dos municípios brasileiros não cumprem essa a previsão do $\mathrm{PNAE}^{7}$.

(viii) Segundo o FNDE, responsável pelo programa, em 2017 a média nacional de aquisição dos produtos da agricultura familiar para a alimentação

\footnotetext{
${ }^{1}$ Disponível em: https://www.gov.br/agricultura/pt-br/assuntos/noticias/cresce-percentual-de-organicos-nascompras-do-programa-de-aquisicao-de-alimentos. 31 mai. 2019. Acesso em: 12 set. 2020.

${ }^{2}$ Ibid.

${ }^{3}$ Ibid.

${ }^{4}$ Disponível em: https://www.gov.br/agricultura/pt-br/assuntos/noticias/mercado-brasileiro-de-organicos- faturar-4-bilhoes. 02 abr. 2019. Acesso em 12 set. 2020.

${ }^{5}$ Disponível em: https:/www.gov.br/agricultura/pt-br/assuntos/noticias/em-sete-anos-triplica-o-numero-deprodutores-organicos-cadastrados-no-mapa. 01 abr. 2019. Acesso: 12 set. 2020. ${ }^{6}$ Ibid.

7 Disponível em: https://www.gov.br/agricultura/pt-br/assuntos/noticias/ministerio-da-agricultura-e-fndequerem-ampliar-a-presenca-de-produtos-organicos-na-alimentacao-escolar. 16 mai. 2019. Acesso em: 12 set. 2020.
} 
escolar por meio do PNAE era de 24\%. Quando se leva em conta os produtos orgânicos, o percentual é ainda menor. A média naci- onal gira em torno de $3,5 \%$ dentro das aquisições da agricultura familiar ${ }^{8}$.

(ix) A coordenadora alerta que o município ou estado que não compra o mínimo de $30 \%$ de produtos da agricultura familiar conforme previsto no Plano fica com ressalvas na prestação de contas que deve ser entregue ao Tribunal de Contas da União (TCU). São Paulo, Paraná e Rio Grande do Sul são os estados que mais compram alimentos da agricultura familiar para as escolas, enquanto que Rondônia aparece com o percentual mais baixo de

\section{Considerações finais} aquisição desses produtos ${ }^{9}$.

Em vista do modelo de colonização empregado no Brasil, baseado na exploração mercantil sob a face de empresa agrícola, este período ainda repercute intensamente hodiernamente. As ocupações territoriais iniciais mais incisivas foram formatadas ao sabor dos ciclos econômicos de maior expressão, experimentados por esta nação (cana-de açúcar no Nordeste, mineração e cafeicultura, no Sudeste). Algo peculiar em todas essas atividades foi a "preciosa" contribuição do trabalho escravo, contudo, nestas últimas, surgiram, respectivamente, a presença do trabalhador livre e o labor imigrante. Perpassando por outros momentos da evolução histórica nacional até o vigor do Estado Democrático de Direito, ainda assim, relativamente à manifesta evolução política, o arcabouço socioeconômico pouco progrediu nestes quinhentos anos.Considerando que a base social colonial se estruturou na zona rural, e é neste espaço que sua interferência é mais evidente, insurge movimentos campesinos reativos ao enfrentamento de abusos seculares. Para acudir esta questão, vislumbra-se, então, na agroecologia como uma atividade camponesa capaz de, concomitantemente, ser portar comoresistência ao modo de produção intensivo e predatório posto, mas também de conciliar o manejo dos recursos naturais e com uma agricultura ecológica lastreada por princípios de desenvolvimento sustentável.

É neste mote, que se torna perfeitamente factível a relevância da agroecologia em quase todos os 17 ODS's, singularmente no ODS2. Em tão alto grau o é que a FAO acaba por elevar a agroecologia como um padrão viável para produção sustentável de alimentos e de preservação da biodiversidade, ao anunciar, em maio de 2018, a Iniciativa para ampliar la escala de la agroecolgía: transformar la alimentación y los sistemas agrícolas apoyo de los $O D S$. Através deste documento, esta entidade indica uma ruptura com um alinhamento, de aproximadamente meio século, com o ideário da "revolução verde" e seu manejo intensivo.

\footnotetext{
${ }^{8}$ Ibid.

${ }^{9}$ Ibid.
} 
No Brasil, na mesma toada de crítica a esta, a PNAPO foi implementada com o fito de integrar e articular políticas públicas às agendas da agroecologia da produção orgânica. Sua instituição se deu paulatinamente alicerçada em governos progressistas, mas com a efetiva participação (pressão) da sociedade civil através de discussões propiciadas pela CNAPO e pela CIAPO. Ou seja, trata-se de uma construção entre governo e sociedade, com abordagem interministerial. E, neste sentido, no âmbito das articulações com outras políticas públicas, tais quais o PAA (Ministério da Cidadania) e o PNAE (Ministério da Educação) importantes estimuladores à produção sustentável e o fornecimento de alimentos saudáveis à população.

Por fim, não se pode deixar de tecer comentários abordando as feiras agroecológicas. Tais são espaços transcendem o local de comercialização para uma atmosfera recheada de relações socias justas para o agricultor familiar e seu parceiro, na qualidade de consumidor de alimentos saudáveis a preços acessíveis. Para tanto, assim como no PAA e no PNAE, o produtor agroecológico deve estar cadastrado e regularizado no MAPA.

Em síntese, a estruturação desta atividade econômica é de grande relevância já que sua função ou utilidade não está restrita ao território produtor e ao mercado local, pelo contrário está inserida na dinâmica de uma conjuntura global. Por ter em seu bojo, fundamentos de desenvolvimento sustentável, a agroecologia desponta como um vetor na melhoria da qualidade de vida das pessoas. Tanto de quem a produz, quanto de quem a consome.

\section{REFERÊNCIAS}

ALTIERI, M. A. Agroecologia: as bases científicas da agricultura alternativa. Rio de Janeiro: PTA/FASE, 1989.

ARAÚJO, T. P.; VIANNA, S. T. W.; MACAMBIRA, J. (Orgs.). 50 anos de formação econômica do Brasil: ensaios sobre a obra clássica de Celso Furtado. Rio de Janeiro: Ipea, 2009.

AZEVEDO, Elaine de; PELICIONI, Maria Cecília Focesi. Promoção da saúde, sustentabilidade e agroecologia: uma discussão intersetorial. Saúde Soc. São Paulo. São Paulo, ano 3, n. 20, p. 715-729, 2011.

BRASIL. Decreto 6.323, de 27 de dezembro de 2007. Diário Oficial da União. Disponível em: <http://www.planalto.gov.br/ccivil_03/_Ato2007-2010/2007/Decreto/D6323.htm>. Acesso em: 11 set. 2020.

BRASIL. Decreto 7.775, de 27 de julho de 2012. Diário Oficial da União. Disponível em: <http://www.planalto.gov.br/ccivil_03/_ato2011-2014/2012/decreto/d7775.htm>. Acesso em: 
12 set. 2020 .

BRASIL. Lei 10.696, de 03 de julho de 2003. Diário Oficial da União. Disponível em: <http://www.planalto.gov.br/ccivil_03/LEIS/2003/L10.696.htm>. Acesso em: 12 set. 2020.

BRASIL. Lei 10.831, de 23 de dezembro de 2003. Diário Oficial da União. Disponível em:<http://www.planalto.gov.br/ccivil_03/leis/2003/110.831.htm\#: :text=LEI\%20No\%2010.83 $1 \% 2 \mathrm{C} \% 20 \mathrm{DE} \% 2023 \% 20 \mathrm{DE} \% 20 \mathrm{DEZEMBRO} \% 20 \mathrm{DE} \% 202003 . \&$ text=Regulamento.,Art.>. Acesso em: 08 set. 2020.

BRASIL. Lei 11.497, de 16 de junho de 2019. Diário Oficial da União. Disponível em: < http://www.planalto.gov.br/ccivil_03/_Ato2007-2010/2009/Lei/L11947.htm>. Acesso em: 12 set. 2020.

BRASIL. Ministério da Agricultura, Pecuária e Abastecimento (MAPA). Disponível em: $<$ https://www.gov.br/agricultura/pt-br/assuntos/sustentabilidade/organicos/regularizacao-daproducao-organica/regularizacao- da-producao>. Acesso em: 11 set. 2020.

BRASIL. Ministério da Agricultura, Pecuária e Abastecimento (MAPA). Guia prático: formação de Organizações de Controle Social (OCS). Série Agricultura familiar: boas práticas replicáveis de comercialização de produtos da sociobiodiversidade e agroecologia. 1 ed. Brasília: MAPA, 2020.

BRASIL. Ministério da Cidadania. Secretaria Especial do Desenvolvimento Social (SEDS). Disponível em: <http://mds.gov.br/assuntos/seguranca-alimentar/programa-de- aquisicao-dealimentos-paa/programa-de-aquisicao-de-alimentos/compra-institucional> .

Acesso em: 12 set. 2020.

BRASIL. Ministério da Educação. Fundo Nacional do Desenvolvimento da Educação.

Programa Nacional de Alimentação Escolar (PNAE). c2017. Disponível em: <https://www.fnde.gov.br/programas/pnae> Acesso: 12 set. 2020.

BRASIL. Resolução $\mathbf{N}^{\circ}$ 6, de 08 de maio de 2020: Ministério da Educação. Diário Oficial da União. Disponível em: <https://www.in.gov.br/en/web/dou/-/resolucao-n-6-de-8-de- maiode-2020-256309972>. Acesso em: 12 set. 2020.

BRASIL AGOECOLÓGICO. Plano Nacional de Agroecologia e Produção Orgânica Planapo: 216-2019. Brasília, DF: Ministério do Desenvolvimento Agrário, 2016. Disponível em: <http://www.mda.gov.br/sitemda/sites/sitemda/files/ceazinepdf/PLANAPO_2016_2019.p df>. Acesso em: 22 jun. 2019.

BRITTO, Débora. Feiras agroecológicas: da escolha individual à política pública. Marco Zero Conteúdo. 08 jan. 2020. Disponível em: <https://marcozero.org/feiras-agroecologicas-da-escolhaindividual-a-politica-publica/>. Acesso em: 11 set. 2020.

CARNEIRO, Fernando Ferreira et. al (Orgs). Dossiê ABRASCO: um alerta sobre os impactos dos agrotóxicos na saúde. Rio de Janeiro: EPSJV, 2015.

FAO BRASIL. Celebrando a contribuição dos agricultores familiares para o Fome Zero e dietas mais saudáveis. c2020. Disponível em: 
<http://www.fao.org/3/I9049ES/i9049es.pdf>. Acesso em: 07 set. 2020.

FAO. Iniciativa para ampliar la escala de la Agroecología. 2018. Disponível em: <http://www.fao.org/brasil/noticias/detail-events/pt/c/1195906/>. Acesso em: 07 set. 2020.

FIORILlO, Celso Antonio Pacheco. Curso de direito ambiental brasileiro. 15 ed. São Paulo: Saraiva, 2015.

FONSECA, Igor Ferraz da and BURSZTYN, Marcel. A banalização da sustentabilidade: reflexões sobre governança ambiental em escala local. Soc. Estado, 2009, vol.24, n.1, pp.1746.

FREYRE, G. Casa grande \& senzala: formação da família brasileira sob o regime da economia patriarcal; apresentação de Fernando Henrique Cardosos. 48. ed. rev. São Paulo: Global, 2003.

FURTADO, C. Análise do modelo brasileiro. Rio de Janeiro: Civilização Brasileira, 1973.

GONÇALVES, Paulo Cesar. Procuram-se braços para a lavoura: imigrantes e retirantes na economia cafeeira paulista no final do Oitocentos. Revista Brasileira de História. São Paulo, vol. 34, n. 67, jan./jun. 2014.

HABERMAS, J. A Ética da Discussão e a Questão da Verdade. Rio de Janeiro: Martins Fontes, 2007.

HOLANDA, Sérgio Buarque de. Raízes do Brasil. 26. ed. São Paulo: Companhia das Letras, 1995.

INSTITUTO DE PESQUISA ECONÔMICA APLICADA. Análise da construção da política nacional de agroecologia e produção orgânica no Brasil. Brasília: Ipea, 2017.

ISAGUIRRE-TORRES, Kátya; FRIGO, Darcy. Desenvolvimento rural, meio ambiente e direito dos agricultores, agricultoras, povos e comunidades tradicionais. Série Cadernos da Agrobiodiversidade. vol. 2. Curitiba: Terra de Direitos, 2013.

LEONEL JÚNIOR, Gladstone. Direito à agroecologia: a viabilidade e os entraves de uma prática agrícola sustentável. Curitiba: Editora Prismas, 2016.

LIMA JÚNIOR, Jayme Benevuto. Os direitos humanos econômicos, sociais e culturais. Rio de Janeiro: Renovar, 2001.

MARTÍNEZ ALIER, J.; SCHLÜPMANN, K. La ecología y la economía. Madrid: Fondo de Cultura Económica, 1992.

NAÇÕES UNIDAS. FAO lista cinco passos para uma alimentação segura. Disponível em: $<$ https://nacoesunidas.org/fao-lista-cinco-passos-para-uma-alimentacao-segura/>. Acesso em: 22 jun. 2019.

ODS2 Fome zero e agricultura sustentável. Disponível em:

<https://nacoesunidas.org/pos2015/ods2/>. Acesso em: 26 jun. 2019. 
A ONU e o meio ambiente. Disponível em: <https://nacoesunidas.org/acao/meio-ambiente/>. Acesso em: 07 set. 2020.

PRADO JÚNIOR, Caio. Formação do Brasil Contemporâneo: colônia. 6. ed. São Paulo: Editora Brasiliense, 1961.

SANTOS, Boaventura de Sousa. Pela mão de Alice: o social e o político na pós modernidade. 7. ed. Porto: Edições Afrontamento, 1999. 